An accurate observer related to me the case of a lady whose iris changed colour in bright sunlight.

These few instances seem to show that the behaviour and properties of pigment-cells are independeni of the protective functions for which they have, in some cases, been specialised and augmented by the action of natural selection.

It seems a pity that Mr. Murphy should write on a question in natural history without making himself better acquainted with what is known on the subject.

Down, Beckenham, Aug. I4

IN the last number of NATURE Mr. J. J. Murphy states the difficulty which he finds in accounting for the rise of intermiltent variations upon the theory of natural selection. He can understand the origin of a white species from a brown one or vice vers $\hat{b}$, but not of a species which, like the ermine, is at one season brown and at another season white. He speaks of "facts of colour which it seems impossible for natural selection to produce, from the infinite improbability of a first variation ever occurring." From this mode of expression one might fancy that Mr. Murphy had for the moment forgotten that natural selection is in no way concerned with producing, but acts only by preserving, variations. As in a great number of instances we are ignorant of the precise antecedents which produce variation, whether chronic or recurrent, in such instances, we must be left at liberty, if we choose, to invole the special action of "a guiding intelligence." The case, however, of an animal which charges its colour with the season does not seem to be one of very exceptional difficulty. It is only necessary to suppose that the animal became possessed of pigments liable to be acted on in the required direction by the seasoral changes of light and heat. It might well be that with some animals the influ. ence of the same changes would be in a direction just the oppo. site of what was useful to them. In that case the variety would stand but little chance of being preserved. Similar explanations hold with regard to the vegetable kingdom. I have now before me drawings of Sempervivum spinosum. The summer rosette is bright green in colour, with the leaves expanded, while the winter rosette is a compact little ball of a dull purple. Thus the plant prepares itself against the cold of winter and the dearth of nourishment which that season brings, but it is likely enough that cold and dearth in the first instance led to the variation in the plant from its summer habit.

In human beings the hair is said sometimes to turn white from sudden grief or terror. Liability to such a change does not probably carry any such advantage to the human species as would make it likely to spread and develop itself further. But in the little shrimp commonly known as Mysis chamcleon, we can at least conjecture that a very solid advantage might follow from a similar characteristic. I have sometimes bottled live specimens of this little creature while it was of a dark purple colour, and presently after lost sight of it, the fact proving to be upon closer inspection that it had become almost completely transparent. Among its ordinary enemies the loss of colour might often save its life, in which case natural selection would tend to preserve the aptitude, although the aptitude itself, like the bleaching of human hair from grief, bas no connection at the ontset with the advantage of the species.

Torquay, Aug. 14

THOMAs R. R. STEBbrNG

Mr. Murphy's letter (NATURE, vol. xiv. p. 309) opens up a wide field for speculation. The class of cases to which he directs attention constitutes what I have designated "variable protective colouring," and in a paper communicated to the Zoological Society (Proc. Zoo. Soc., I872), I attempted to show that such cases came to a certain extent within the scope of natural selection. The line of argument pursued is briefly as follows:-Natural selection, working solely for the good of a species takes advantage of all beneficial variations, no matter how they may originate. In but very few cases can the cause of any particular variation be assigned. Natural selection works only on the variations presented to it, the causes of such variations appearing to us, in the absence of observational or experimental evidence, mysterious. If, then, a species deriving acivantage from protective colouring under one set of conditions, finds that the conditions vary periodically or irregularly, thus rendering that mode of colouring useless or even disadvantageous, it clearly becomes advantageous to the species to possess a power of adaptation. By this means only can varying external conditions be met, and it is upon this adaptive power that $I$ venture to think the action of natural selection has in these cases been exerted. That the particular cause of such variation cannot be assigned, no more weakens th 2 natural selection argument in these than in ordinary instances of permanent protective colouring the possibility of which having been brought about by the "survival of the fittest," Mr. Murphy seems disposed to admit.

One argument in favour of the natural selection theory of protective colouring appears, so far as I am aware, to have been overlooked. It has been urged that granting the power of natural selection to produce a general resemblance in colour, \&c., to inanimate objects, it is difficult to see how the highly perfect finishing touches (instances of which are familiar to all naturalists) could have been imparted by this same agency. To this it may be replied that the marvellously perfect resemblances which we witness have not been brought about to deceive our visual sense, but that of far keener-sighted foes whose very means of subsistence may depend upon acuteness of vision.

Apropos of Mr. Power's letter in the same number of NATURE, I have recently had an opportunity of observing how closely the larva of Trachea piniperda resembles in the longitudinal green stripes the needle-shaped leaves of the pine on which it feeds. I observed also an equally good adaptation in a larva of Agriopis aprilina, which when resting on a lichen-covered oak trunk was barely discemible from the lichen on which it rested.

Belle Vue, Twickenham, Aug. 12

R. Meldola

\section{Antedated Books}

THE grievance pointed out by your correspondent "F.Z.S." is a real one. Nevertheless I trust that the writer is himself free from the charge that he so glibly brings against a brother naturalist of endeavouring to obtain for his generic titles an "unjust priority of fifteen months over what they are entitled to." I am sorry that there should be a. Fellow of the Zoological Society who believes me capable of doing this, but, as the charge has been thus publicly made, I lose no time in flinging it back upon my anonymous accuser. The new edition of Layard's "Birds of South Africa "was announced to appear in six parts, and the first was published in May, 1875. The number of wrappers required for the six parts was printed off at the time, and "F.Z.S." will find that Part 2 , which was published last autumn has precisely the same wrapper as $I^{2}$ art $I$, and this is the case with the part now issued. I admit that it would have been better to have altered the date on each wrapper in writing; but this, probably, did not occur to my publisher, who is doubtless not aware of the importance attached to the law of priority by "F.Z.S." your correspondent, who, apparently, in his hurry to at look beyond the cover of the book. Had he done so he might have been satisfied that the letterpress contained abundant evidence of having been written long after the date which he would have the scientific world believe I had endeavoured to claim for its publication. Such an attempt would be absurd when documents are quoted in the letterpress which were not in existence in the year 1875 .

May I at the same time reply to a paragraph of your reviewer (p. 318 ) on the "Birds of Kerguelen Island." This pamphlet deserves all the praise which the reviewer bestows on it, but in his endeavour to disparage his own comtrymen, and to trumpet the superior energy of American ornithologists, he seems to have done an injustice to Mr. Eaton and myself. Two new species were mentioned by Dr. Coues, viz., Estrelata kidderi, which Mr. Salvin (Orn. Misc., p. 235) shows to be IE. brevirostris (Less.), and secondly, Querquedula eatoni (Sharpe). This latter name looks as if the English ornithologists had not been so far behind their American brethren, after all, if the description of the new Teal was available for quotation in Dr. Coues work!

British Museum

R. BOWDLER SHARPE

FULLY agreeing with "F.Z.S." in reprobating the evil practice of which be complains, I think that in the particular instance he cites, of the recently published third part of the new edition of "The Birds of South Africa," he will, on looking again at its wrapper, see that the information it affords is so contradictory as to be worth nothing. The first words upon it are "To be completed in Six Parts;" but on its second page we read that the publisher " has decided upon issuing this work in four parts!" Which of these statements is to be believed? In justice to the publisher, however, it is to be observed that the number " 3 " is not printed, but inserted with the pen, in the 